\title{
First additional language teaching in the foundation phase of schools in disadvantaged areas
}

\begin{abstract}
Second language learning in South African schools is of supreme importance given the multilingual nature of the country. However, there is no certainty that teachers in the foundation phase of schools in poor environments have the skills to teach literacy in the first additional language and produce competent learners. This investigation revealed that the methods that teachers used to teach English, as the first additional language did not develop children's comprehension and communication skills. It argues that if teachers do not use methods that encourage children to communicate in English the children might not acquire the competence needed to use English as the language for learning in Grade 4. Policy makers are advised to monitor the implementation of the first additional language policy and to oversee the development of an English literacytraining programme in the foundation phase that could provide teachers with the necessary skills and appropriate approaches for teaching the target language.
\end{abstract}

Keywords: first additional language; second language, English competency, foundation phase

Ellen Lenyai, University of South Africa.E-mail: Lenyaem@unisa.ac.za.

South African Journal of Childhood Education | 2011 1(1): 68-81| ISSN: 2223-7674 | @ UJ

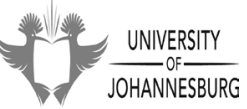




\section{Introduction}

In a multilingual country like South Africa it is important that learners reach high levels of proficiency in at least two languages, and that they are able to communicate in other languages (Department of Education, 2002: 4). The new Curriculum and Assessment Policy Statement (CAPS) (DBE, 2010) for the first additional language, Grades R-3, is founded on this perspective and recommends the additive bilingual approach to the teaching of an additional language. This approach assumes that children start school competent in their home language and that they can use their home language to learn an additional language. However, this statement must be read with caution and it must not influence teaching since it is concerned with assumptions and not proven facts. The CAPS is an improvement of and replaces the Revised National Curriculum Statement, Grades R-9 (NCS) of the Department of Education (2003). It states that by the end of Grade 3 children must reach a high level of communicative competence and be able to read well (DBE, 2010: 7-9).

The implication of these policies is that teachers must have good knowledge and skills to guide learners to develop communicative and reading skills in the first additional language, which in this case is English. However, having observed learners' lack of comprehension and poor communication skills, there is no reason to substantiate that teachers have the expertise to teach English. For the purpose of this research, a competent learner is one who understands and speaks English confidently and who has the ability to use it correctly in various situations.

Research on the teaching of literacy in the first additional or second language at disadvantaged schools is scant while most (Brock-Utne, 2007: 509-526; Hunt, 2007: 81-83; Pretorius \& Mampuru, 2007: 38-40) has focused on English as the Language of Learning and Teaching (LoLT). On the contrary, the emphasis in the current study was on the teaching of English literacy in the foundation phase and not on English as a LoLT.

The question was whether teachers in the foundation phase taught English literacy to promote communication skills and to prepare children to use it as a LoLT in Grade 4. The important issue for teachers therefore is to know how to teach the skills. The starting point for teachers therefore should be to know why English literacy was taught because that could influence how they teach it. It is not sufficient to know that children must be able to read and write by the end of Grade 3, the purpose or motive must also be known (Myers-Scotton, 2006: 9; Pence \& Justice, 2008: 304-313; Schmitt, 2008: 292-293). If teachers knew that children must read with comprehension so that they can talk about what they have read, they would select teaching methods that would promote listening for comprehension, and verbal interaction to promote communication. When English is taught to facilitate assimilation into a new culture for instance, the total immersion approach is recommended because the approach steeps children into the English language and culture. In this case the issue is literacy, implying that it is an introduction to English and attention must be on comprehension and communication skills. Functional methods such as the communicative and Total 
Physical Response (TPR) could be applied because they emphasise comprehension and communication skills.

If children do not comprehend, they might not be able to communicate in English. Children who cannot communicate often cannot read and write efficiently because speaking must develop before reading. They might also not be in the position to decode the language of English textbooks and experience learning challenges in Grade 4 onwards. A literature review on the teaching of the first additional language was used as conceptual framework to support the standpoint that teachers must have the skills to promote comprehension and communication skills if they are to develop children who are competent in English.

\section{Literature review}

The point of departure here is that in order to promote communication and reading comprehension, it is necessary to know the theories, approaches and methods that explain how to teach (Haley \& Austin, 2004: 44-50) and know what language inputs to make (Ellis, 1996: 142-152). The danger of a lack of knowledge in this regard could lead to teachers' choice of inappropriate content and the use of unsuitable teaching approaches. The views of structural theories represented by the grammar and audiolingual methods together with that of functional theories such as the communicative and the TPR methods gave rise to the perception and provided the basis for discussions.

Based on the same analysis the CAPS does not recommend the grammar and the audio-lingual methods and regards them as suitable for teaching language structures and pronunciation, but suggests that they should be taught incidentally as part of reading and writing (DBE, 2010: 18). A notable thing regarding these approaches is that they produce children with abilities that differ from that of children taught through the functional methods mainly because they cannot communicate in the second language (Boakye \& Southey, 2008: 7-21).

The curriculum policy on additive bilingualism in South Africa is based on the functional theories and recommends the use of the TPR and communicative methods (DBE, 2010: 11), which are currently regarded as most suitable methods. It is advisable for teachers therefore to use these methods to develop children's communicative skills and at the same time teach concepts that will prepare children to engage with subject matter presented in English in Grade 4 (DBE, 2010: 18). It means that children must be exposed to a lot of spoken language for developing listening skills and must be provided with many opportunities to use the language to develop speaking skills (DBE, 2010: 10-11).

The key to achieving the goal for English literacy lies in teacher expertise. Pence and Justice (2008: 304-313) point out that good teachers promote language learning by recognising that learners make errors when they learn, but that they ultimately correct the incorrect utterances once they are given the opportunity to do so. The teachers accept nonverbal language and reward telegraphic language and short 
phrases because they are aware of the system in language learning (Baker, 1996: 283; Myers-Scotton, 2006: 9). They allow language learning to go through the stage of home language use when learners are still building vocabulary.

While the use of the home language is said to aid the acquisition of the target language, it must not be regarded as a condition for learning the language. The statement that competence in the home language can be transferred to learn the first additional language (DBE, 2010: 8; Ellis, 1996: 20-26) is contentious because in the case of African languages, there is a big difference from English and the idea of transfer does not seem feasible. The possibility of language transfer needs to be debated given the language situation in South Africa and the statement in the CAPS. Similarly, the theory that the home language interferes (Kilfoil, 1997: 18-19) in the morphology of the target language is questionable because the language structures of African languages are very different from those of English. What seems more apparent is the impact of the accent of African languages on the spelling of English words such as 'sheep' and 'ship' which most African children pronounce the same. The claim also needs further debate and substantiation.

Strategies or techniques that could be used to promote English literacy include songs which are seen to increase vocabulary, stories that are usually regarded as most suitable for encouraging young learners' oral abilities, and conversation for putting language structures in place (Gunning, 2005: 532; Isenbarger \& Willis, 2006: 125). The success of the strategies however would depend on teachers' skill, for instance, of integrating a strategy with content.

\section{Methodology}

The research adopted a qualitative approach, with some of the interview questions being quantitative in nature in order to establish the extent of the problem. The qualitative approach was regarded as suitable because it provided descriptive data needed to answer the research question. It was also suitable for reporting observed learning environments and lesson activities. Interviews were used to elicit information on teachers' use of the curriculum and to understand the reasoning behind their practice. The interview responses were analysed to establish the extent to which they could be regarded as a concern in the teaching of English literacy. Adopting a twopronged approach would not only ensure the validity of the research results, but could confirm their reliability as well. The aim was to establish how literacy in English as the first additional language was taught at foundation phase level.

Classroom visits for listening and observing how teachers presented English lessons proved to be a useful way of determining which theories, approaches, methods and teaching techniques were applied. The thinking was that teachers might use the methods consciously or unconsciously thus influencing their way of teaching, the rate of children's learning and the achievement of competence (Boakye \& Southey, 2008: 8-9; Brock-Utne, 2007: 509-526; Gunning, 2005: 534; Hunt, 2007: 81-83; Potter, 2007: 172-173; Pretorius \& Mampuru, 2007: 40-41). Although many of the teachers 
did not introduce their lessons, particular attention was still given to the way that some teachers did because it predicted the content and approach to the lesson. The content of the lessons and the involvement of the children in the lesson helped clarify the conceived idea about the teaching. Learners' books were regarded as valuable artefacts that would reveal past and present work done.

Extraneous variables such as the language environment of learning and classroom resources were noted as they could have had an impact on the teaching process and learning outcome. Other such factors included teacher training, qualifications and teaching experience.

The sample comprised a total of 30 teachers drawn from 10 primary schools at townships in the Gauteng province. The schools were purposefully selected because they were typical township schools and were accessible. Three teachers were randomly selected per school, one from each grade. The necessary ethical issues were considered.

\section{Research findings}

\section{Teacher profile}

Three questions were asked:

- Where did you obtain your teachers certificate?

- How many years have you been teaching in the foundation phase?

- To which age group do you belong?

Table 1: Teachers' training by institution

\begin{tabular}{|c|c|c|c|}
\hline Training College & University & Training College \& University & Other \\
\hline 17 & 4 & 9 & 0 \\
\hline
\end{tabular}

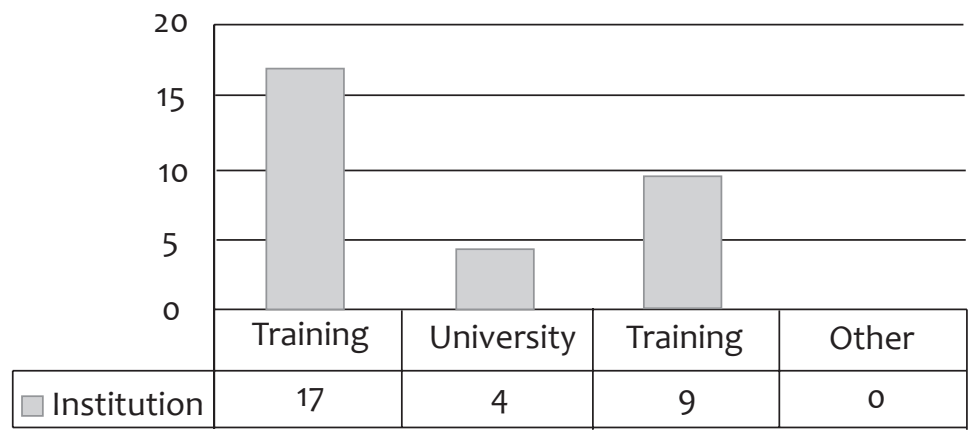


A total of 17 teachers received their three-year certificates at training colleges of education. Four obtained two-year diplomas at universities and nine had college qualifications consisting of a one-year university certificate. None had other qualifications such as those held by non-governmental organisations. The qualification profile that emerged was not regarded as a possible threat to English literacy teaching because it satisfied the required standard.

Table 2: Years of teaching experience

\begin{tabular}{|c|c|c|c|c|c|}
\hline $1-5$ & $6-10$ & $11-15$ & $16-20$ & $21-25$ & $26-30+$ \\
\hline 2 & 8 & 11 & 3 & 3 & 3 \\
\hline
\end{tabular}

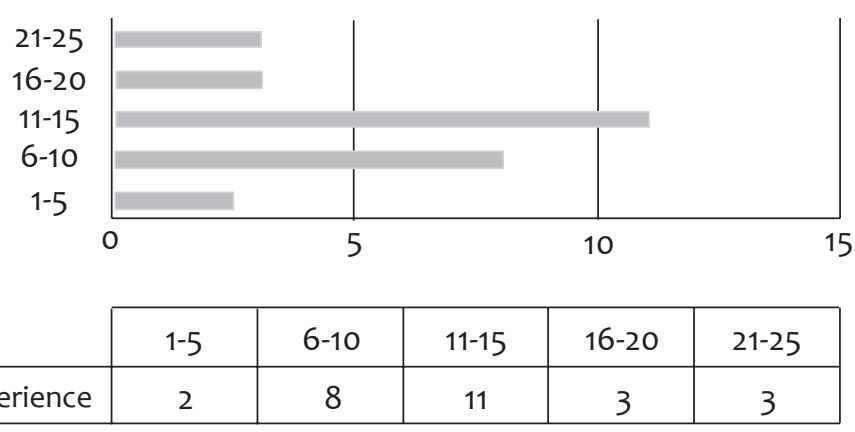

Figure 2: Teachers' years of experience in the foundation phase.

Teachers' years of teaching experience as indicated in Table 2 and in Figure 2 was also not a cause for concern. It reflected a mature teacher cohort that could prove to be responsible and dedicated. Only two had experience of five years or less. Eight had six to 10 years' teaching experience while a notable 11 had 11 to 15 years' experience. An encouraging finding was that three teachers each represented the categories of 1620, 21-25 and 26 to 30 years' experience. The position in this research is that they were seasoned teachers who could serve as role models and provide good advice to those experiencing obstacles.

Table 3: Teachers' ages, teaching experience, and institutions of training

\begin{tabular}{|c|c|c|c|c|c|}
\hline $20-30$ years & $31-40$ years & $41-50$ years & $51-60$ years & $61-65$ years & Total \\
\hline 3 & 14 & 7 & 4 & 2 & 30 \\
\hline
\end{tabular}




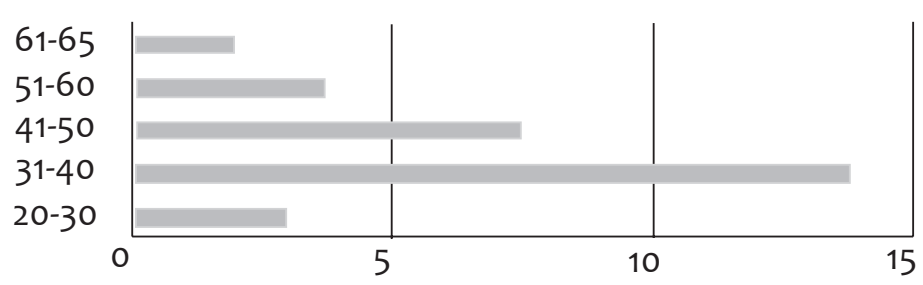

\begin{tabular}{|c|c|c|c|c|c|}
\cline { 2 - 6 } \multicolumn{1}{c|}{} & $20-30$ & $31-40$ & $41-50$ & $51-60$ & $61-65$ \\
\hline Ages & 0 & 14 & 7 & 4 & 2 \\
\hline
\end{tabular}

\section{Figure 3: Teachers' Ages}

A majority of 14 teachers were within the 31-40 years age group. Seven were between the 41 and 50, four between 51 and 60 years, two between 60 and 65 years and only three were in the 20 to 30 -age range. Teachers in these age ranges could be regarded as mature and stable in their career and should be able to perform well.

Since neither teachers' qualifications nor their teaching experience or age were seen as possible threats to teaching success, there was more reason to investigate the approaches, methods and techniques used to teach English literacy as factors that could influence the success of producing competent learners.

\section{Observation results}

The empirical investigation revealed not only how literacy in English was taught, but also what was done in the different grades. Nothing was taught in Grade 1 because teachers were focusing on teaching reading in the home language. In Grade 2 a few English words were sometimes taught, but virtually nothing was done in this Grade as well. In Grade 3 children were required to fill in one missing word in a sentence or matching a picture with the correct word. In other words attention was on structural issues such as building vocabulary and drilling correctness of grammar. This approach did not provide opportunity for children to engage in English and thus did not promote communicative skills (Boakye \& Southey, 2008: 7-21).

Teachers who emphasised the pronunciation of words with little focus on comprehension guided book reading, dominated reading lessons. Children each had a turn to read, but rarely discussed the content of the book. What was observed resembled the activities associated with the grammar and audio-lingual methods and strengthened the opinion that it was the approach followed by the teachers. It also seemed that creative writing in the form of paragraphs was not practised and the children's books showed no evidence to the contrary.

In general, there was no certainty that the recommended teaching approaches such as the communicative and the TPR were employed. Teachers dominated lessons and rarely afforded the children time to speak except when answering questions. 
Although stories were read, they featured as part of a reading lesson and were rarely used as a source for discussion. Systematic planning of lessons was not prominent and it was difficult to notice progression in the content of the lessons.

\section{Interview findings}

The following are the findings of interviews with teachers in the research.

Table 4: Approach to second language teaching

\begin{tabular}{|l|c|c|}
\hline & Yes & No \\
\hline Question 1. Do you use a specific method to teach English? & 0 & 30 \\
\hline
\end{tabular}

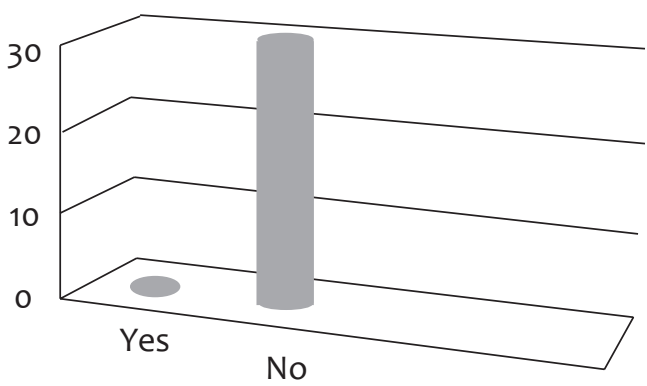

\section{Figure 4: Question 1}

Table 4 and Figure 4 show that all the teachers did not use a specific method for teaching first additional language.

None of the 30 teachers indicated they used a specific method to teach English. When probed further about other methods, all of them replied, "Which methods?" and indicated that they were not aware of "special methods" for English. The fact that all 30 gave the same response shows that the extent of the problem may be wide and would best be addressed by the DBE. It could also suggest that teachers might not have received sufficient training to apply language theories since all of them received training at colleges of education. This gap could reduce their teaching ability. As indicated, English literacy was not a priority in Grades 1 and 2 because teachers believed that learners must first acquire reading skills in their home language so they could transfer the knowledge to the additional language; an issue that was refuted earlier. 
Table 5: Methods used for teaching reading in English

\begin{tabular}{|l|c|c|c|}
\hline & Phonics & Whole word & Other \\
\hline $\begin{array}{l}\text { Question 2. Which reading methods do you use } \\
\text { to teach reading and writing in English? }\end{array}$ & 30 & 2 & \\
\hline
\end{tabular}

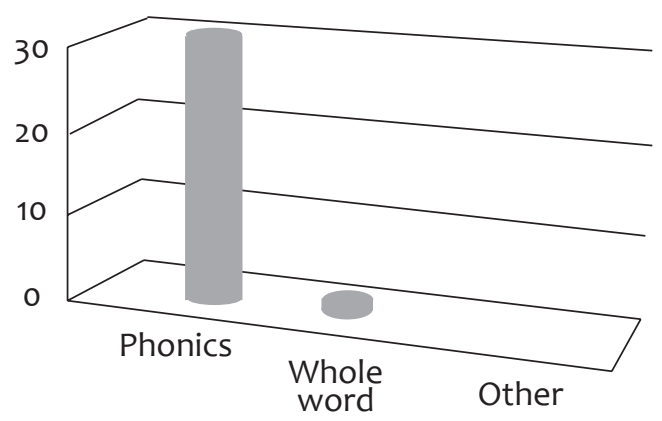

\section{Figure 5: Question 2}

Table 5 and Figure 5 indicate that the majority of teachers used phonics for teaching English reading and two used both the phonics and the whole-word approaches.

While phonics is a good method of teaching reading (Bouwer, 2004: 94-96) it does not highlight meaning, but deals with the elements of sounds in a word to enable children to read. If teachers understood that English literacy was taught to promote communication skills and to prepare children to use it as a LoLT in Grade 4, they might have considered including other approaches. The whole word, the sentence, or the language approaches could have been used too since the methods pay attention to meaning that is central to communication. The apparent belief that phonics alone is good to teach reading, needs to be addressed because it affected all the teachers.

Table 6: Teaching of language forms

\begin{tabular}{|l|c|c|}
\hline & Yes & No \\
\hline Question 3. Do you teach all the forms of language? & 3 & 27 \\
\hline
\end{tabular}




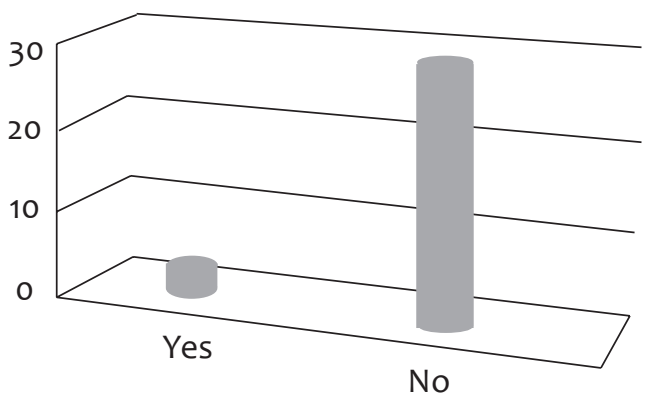

Figure 6: Question 3

Table 6 and Figure 6 show the extent to which language forms previously referred to as outcomes in the NCS were taught.

The CAPS (DBE, 2010) document has moved away from the concept of 'outcomes' and refers to them as listening, speaking, reading and writing as language skills or forms. Only three teachers reported teaching all the language forms and 27 indicated they could not cover all. This may be an indication that 27 teachers did not understand the interrelatedness of the different language forms and could therefore not plan literacy lessons properly. The observed unsystematic lesson plans could be a manifestation of this confusion. The total of 27 raises a concern regarding teachers' ability to teach English literacy since it averages $90 \%$ of all teachers and is significantly above the $30 \%$ that seemed to understand.

Table 7: Challenges encountered in teaching

\begin{tabular}{|l|c|c|c|c|}
\hline & $\begin{array}{c}\text { Letters and } \\
\text { words }\end{array}$ & Comprehension & Speaking & $\begin{array}{c}\text { Reading and } \\
\text { writing }\end{array}$ \\
\hline $\begin{array}{l}\text { Question 4. } \\
\text { In which } \\
\text { language } \\
\text { areas do you } \\
\text { encounter } \\
\text { challenges } \\
\text { when you teach } \\
\text { English? }\end{array}$ & 15 & 28 & 30 & 15 \\
\hline
\end{tabular}




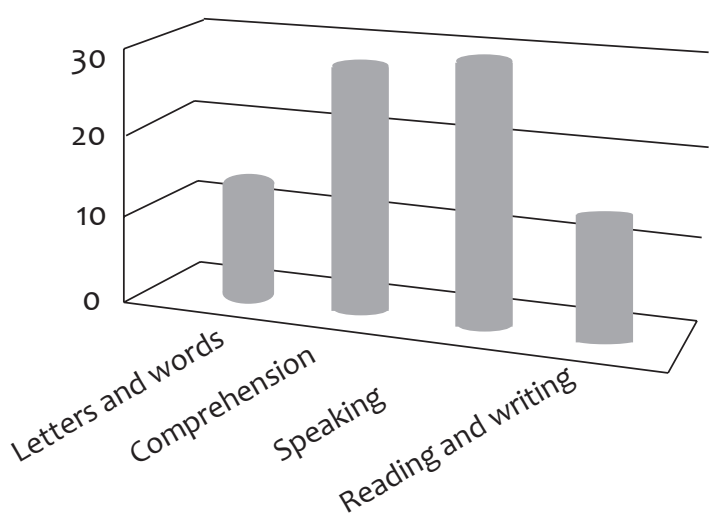

Figure 7: Question 4

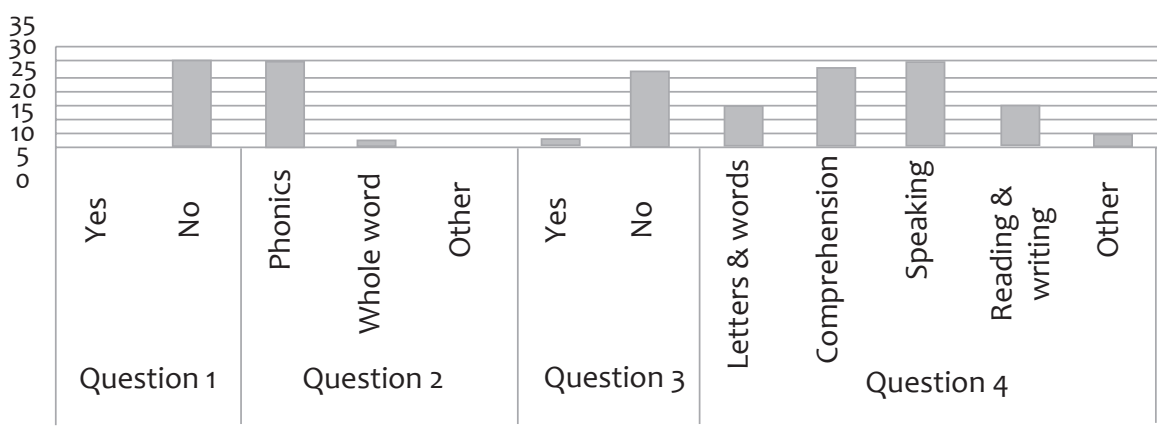

\section{Figure 8: Interview questions}

Table 7 shows the problem areas experienced by teachers in teaching English literacy.

Of the 30 teachers, 15 experienced problems teaching letters of the alphabet and words, 28 with teaching comprehension, 30 with teaching speaking and 15 with teaching reading and writing. The language aspects referred to above constitute the core of any language. When 28 teachers admit they have difficulty in teaching comprehension and 30 with teaching speaking skills, it means teachers' expertise must be considered a serious concern since comprehension and communication (speaking) are the essence of English literacy. The fact that these results resemble those of Hugo's research (2008: 63-75) in the same field causes more anxiety and calls for immediate attention.

\section{Conclusion and recommendations}

From the observation and interview responses, it was evident that teachers in the research gave English literacy very little time and used the grammar and audio-lingual 
methods for teaching. The lack of verbal interaction with learners during English lessons, teachers' focus on grammar correctness and emphasis on words rather than on passages or book texts, all pointed to the use of the methods. A very important indicator of the use of these methods was the fact that the learners in the research study could not communicate in English (Boakye \& Southey, 2008: 7-21; Fleisch, 2008: 97-98; Schmitt, 2008: 292-293).

The answer to the question whether teachers in the foundation phase taught English literacy to promote communication skills and to prepare children to use it as a LoLT in Grade 4 is a negative one because of the poor communication skills. There was also no proof that the children were reading with understanding or were just parroting the words, as the teachers did not ask questions to check comprehension. A major contributory factor to the failure is teachers' beliefs that knowledge of reading in the home language is a prerequisite for reading in English because they postponed teaching it in Grade 1 and did not emphasise it in Grade 2. It also appears as if the purpose for teaching English literacy in the foundation phase eluded the teachers because the centre of their argument was children's reading ability. If they had understood that the essence of English literacy was comprehension and communication they might have realised the importance of promoting listening and speaking first from Grade $R$ and then introducing reading in Grade 2 after the skills are acquired.

One of the key factors in developing English competency is to start early (Gunning, 2005: 534; Potter, 2007: 171-172) and to proceed systematically (Pence \& Justice, 2008: 299) observing all the learning stages (Baker, 1996: 283). For disadvantaged learners who are said to have limited vocabulary even in the home language, whose general linguistic abilities are regarded as below that of their peers (Hawken, Johnston \& McDonnell, 2005: 232), and whose parents are illiterate (Anthony, 2008: 473), learning English literacy for the first time in Grade 3 is too little too late. Grade 3 teaching should emphasise independent reading and good writing skills.

The following recommendations may be useful to address the noted problems. First, teacher development for teaching a first additional language must be made a priority so they can implement the CAPS successfully. Teachers must be made aware of the purpose for teaching English literacy and encouraged to start teaching it from Grade $\mathrm{R}$ for reasons already explained. Secondly, the grammar and audio-lingual methods should not be the main teaching methods, but should be incidental in reading and writing lessons. Thirdly, teachers must be taught that language is best learned systematically through listening, speaking, reading and finally writing. In writing, their role in assessment should first be to identify the meaning that children are trying to convey and only much later in Grade 3 attend to language structures and spelling.

It would therefore be advisable to expose teachers to progressive methods such as the TPR and the communicative approach for teaching English competency. For the children, learning English should be fun. The DBE could consider forging partnerships with institutions of higher learning who can provide in-service teacher training in the 
first additional language, which must include content on theories and methods of teaching English or any second language.

Policy makers should ensure that what is contained in the CAPS foundation phase First Additional Language Grades $\mathrm{R}-3$ is translated into practice correctly at provincial level and is filtered through to local level unambiguously. Measures must be put in place to continuously assist and monitor teachers in their effort to promote English literacy and to prepare children to use it as a LoLT in Grade 4.

\section{References}

Anthony, A. R .B. (2008). Output strategies for English language learners: theory and practice. The Reading Teacher, 61(6): 472-482.

Baker, C. (1996). Foundations of bilingual education and bilingualism. 2nd ed. Clevedon, Canada: Library of Congress.

Boakye, N. \& Southey, L. (2008). Investigating students' motivation and attitudes towards reading. Journal for Language Teaching, 42(2): 7-22.

Bouwer, C. (2004). Reading and writing. In: L. Eloff and L. Ebersöhn (eds.), Keys to educational psychology. Cape Town: UCT Press.

Brock-Utne, B. (2007). Language instruction and student performance: new insights from the research in Tanzania and South Africa. International Review of Education, 53: 509-530.

Department of Basic Education (DBE). (2010). Curriculum and Assessment Policy Statement (CAPS). Pretoria: DBE.

Department of Education. (2002). The Revised National Curriculum Statement Grades R-9 (schools) Policy languages: English - first additional language. Pretoria: DoE.

Department of Education. (2003). The Revised National Curriculum Statement Home Languages for Grades R-9: Teacher's Guide for the development of learning programmes. languages. Pretoria: DoE.

Fleisch, B. (2008). Primary education in crisis. Cape Town: Juta.

Haley, M. H. \& Austin, T. Y. (2004). Content-based second language teaching and learning. An interactive approach. Boston: Pearson education Inc.

Ellis, R. (1996). Understanding second language acquisition. New York: Oxford University Press.

Gunning, G. T. (2005). Creating literacy instruction for all students. Boston: Library of Congress.

Hawken, L. S., Johnston, S .S. \& McDonnell, A .P. (2005). Emerging literacy views and practices: results from a national survey of head start preschool teachers. Topics in Early Childhood Special Education, 25(4): 232-242. 
Hugo, A. J. (2008). Primary school teachers' opinions of their ESL learners' language abilities. Journal for Language Teaching, 42(2): 63-75.

Hunt, G. (2007). Failure to thrive? The community literacy strand of the additive bilingual project at an Eastern Cape community school, South Africa. Journal of Research in Reading, 30(1): 80-96.

Isenbarger, L. \& Willis, A. I. (2006). An intersection of theory and practice: accepting the language a child brings into the classroom. Language Arts, 84(2): 125-135.

Kilfoil, W. R. \& Van der Walt, C. (1997). Learn 2 teach. English language teaching in a multilingual context. Pretoria: Van Schaik.

Myers-Scotton, C. (2006). Multiple voices: An introduction to bilingualism. Oxford: Blackwell.

Pence, K. L. \& Justice, L. M. (2008). Language development from theory to practice. Columbus, Ohio: Pearson Merrill Prentice Hall.

Potter, C. A. (2007). Developments in UK early years policy and practice: can they improve outcomes for disadvantaged children? International Journal of Early Years Education, 15(2): 171-180.

Pretorius, E. J. \& Mampuru, D. M. (2007). Playing football without a ball: language, reading and academic performance in a high poverty school. Journal of Research in Reading, 30(1): 38-58.

Schmitt, N. (2008). Instructed second language vocabulary learning. Language teaching research, 12(3): 329-363. 